\title{
La metafísica inmortalista
}

Raúl Antelo ${ }^{\bullet}$

Universidade Federal de Santa Catarina

\section{Resumen}

Propongo leer dos textos del escritor español Ramón Gómez de la Serna (1988-1963). En el primero, el fetiche (Pompeya) incrementa su efecto milagroso por el hecho de que pocos de los que creen en él lo han llegado a ver. El segundo, sobre un aura liberada, muestra que solo se llega a la vida por medio de la sobrevivencia como entrelazamiento de vida y muerte, es decir, la autoinmunidad de la mortalidad.

\section{Palabras clave}

- Destrucción · Huellas · Inmortalidad

\begin{abstract}
I propose to read two texts by Spanish writer Ramón Gómez de la Serna (1988-1963). In the first one, the fetish (Pompei) is a lot more miraculous as only a few of those who believe in it have seen. The other one, on a free aura, shows that life can only be given through the movement of survival as an intertwinement of life and death, i.e., an autoimmunity of mortality.
\end{abstract}

\section{Keywords}

- Destruction - Traces - Immortality 
Vou lhe contar um segredo: a vida é mortal. Vou ter que interromper tudo para te dizer o seguinte: a morte é o impossivel e o intangivel. Clarice Lispector, Agua viva (1973)

\section{Nuestra marcha sin querellas}

La historia colonial (Kolonialgeschichte) de Europa, escribía Walter Benjamin en 1929, al reseñar el libro de Marc Brion sobre el padre Las Casas, comienza con el monstruoso proceso de la Conquista, que convierte al Nuevo Mundo en una inmensa sala de tortura (Folterkammer). En esa imagen fuerte y premonitoria ${ }^{1}$, se detectan entonces los principales elementos de una teoría de la memoria en nuestro autor. En efecto, la memoria (Gedächtnis) no es, para Benjamin, un instrumento para recuperar informaciones pretéritas, sino una experiencia de rescate de lo vivido en cuanto imagen. Lo dejará más claro en un pequeño texto de 1932:

La lengua determinó en forma inequívoca que la memoria no es un instrumento para la exploración del pasado, sino solamente el medio ${ }^{2}$. Así como la tierra es el medio en el que yacen enterradas las viejas ciudades, la memoria es el medio de lo vivido. Quien intenta acercarse a su propio pasado sepultado tiene que comportarse como un hombre que excava. Ante todo no debe temer volver siempre a la misma situación, esparcirla como se esparce la tierra, revolverla como se revuelve la tierra. Porque las «situaciones» son nada más que capas que solo después de una investigación minuciosa dan a luz lo que hace que la excavación valga la pena, es decir, las imágenes que, arrancadas de todos sus contextos anteriores, aparecen como objetos de valor en los aposentos sobrios de nuestra comprensión tardía, como torsos en la galería del coleccionista. Sin lugar a dudas es útil usar planos en las excavaciones. Pero también es indispensable la palada cautelosa, a tientas, en la tierra oscura. Quien solo haga el inventario de sus hallazgos sin poder señalar en qué lugar del suelo actual conserva sus recuerdos, se perderá lo mejor. Por eso los auténticos recuerdos no deberán exponerse en forma de relato sino señalando con exactitud el lugar en que el investigador se apoderó de ellos. Épico y rapsódico, en sentido estricto, el recuerdo verdadero deberá, por lo tanto, proporcionar simultáneamente una imagen de quien recuerda, así como un buen informe arqueológico debe indicar ante todo qué capas hubo que atravesar para llegar a aquella de la que provienen los hallazgos. (Benjamin, 1992b:118-119)

El centro, por tanto, es el recuerdo (Erinnerung) entendido como interiorización de esa experiencia de choque, que es siempre fragmentaria (meros «torsos ${ }^{3}$ en la galería del coleccionista»). Sabido es que Benjamin eligió cuatro centros urbanos, París, Berlín, Moscú y Nápoles ${ }^{4}$, como campos específicos de experimentación teórica. En su visita a esta última ciudad, en 1925, destaca el pasaje en que se evoca 
a Pompeya (a partir de un fragmento, justamente) porque la ciudad obliterada surge con y a través del lenguaje:

Uno de los viejos guía y acerca su linterna a un fragmento de frescos pertenecientes a los albores del cristianismo. Entonces hace sonar la palabra «Pompeya», centenaria y mágica. Todo lo que el extraño anhela, admira y paga, es «Pompeya». «Pompeya» vuelve irresistible la imitación de yeso de los restos del templo, la cadena de masa de lava y la persona piojosa del guía. Lo que incrementa el efecto milagroso de este fetiche es el hecho que la mayoría de los que creen en él, no lo han visto nunca. Es comprensible que se le construya un nuevo santuario flamante y costoso a la milagrosa Virgen que reina allí. Es en esta obra y no en la de los Vettii donde vive Pompeya para los napolitanos 5 . (Benjamin, 1992a:15)

El fragmento (de imagen y de lenguaje: el texto) impone así una teoría circular del tiempo, semejante a la que, simultáneamente, exponía Ramón Gómez de la Serna (1999:768): «en el alba más antigua está el alba más moderna. En Pompeya pensaba yo: "En el alba, Pompeya es la Pompeya de su tiempo", y aquí pienso que esta es también el alba primitiva de Pompeya o de la desconocida capital de la Atlántida». Pompeya es entonces un conjunto de mesetas mnemónicas que solo después de una investigación minuciosa nos revela las auténticas imágenes dialécticas arrancadas de todo contexto anterior.

Pero, ¿por qué la irrupción de lo ya pasado ocurre en ese momento? Hacia 1928, un conjunto de acciones estéticas nos indican un claro cambio de paradigma historiográfico. Se retraen el positivismo y la evolución y se afirma en cambio una nítida concepción circular del tiempo. Federico García Lorca pronuncia en 1927 su célebre conferencia «La imagen poética de Don Luis de Góngora», en sintonía con el proyecto de edición de las obras del poeta, en su cuarto centenario, a cargo de Dámaso Alonso y José María de Cossío. Ese mismo año, en el marco de las conmemoraciones, Ortega y Gasset adhiere con el ensayo «Góngora (1627-1927)», luego incluido en El espiritu de la letra y, al año siguiente, Eugenio d'Ors propone Las ideas y las formas, pero son asimismo de 1927 los ensayos Southern Baroque Art, de Sacheverell Sitwell, y «Apologie de l'art baroque», de Jean Cassou. De 1927 es La Torre, de Hugo von Hofmannsthal, versión de La vida es sueño, reseñada por Benjamin como postrera manifestación del Trauerspiel. De ese mismo año también son las Cuestiones gongorinas de Alfonso Reyes y el número especial de Martín Fierro dedicado a Góngora, con intervenciones de Jorge Luis Borges y Pedro Henríquez Ureña, entre otros; poco posterior, la revista Libra (1929), dirigida por Francisco Luis Bernárdez y Leopoldo Marechal, donde Reyes releva la suerte de Góngora en América. Finalmente, es de 1928, quizás el texto más relevante de todos, secuestrado hasta edición posterior, años 60 y 70, Origen del drama barroco alemán, de Walter Benjamin (Diaz, 2015; 2016:113-126). Y si Góngora marcaba la división de aguas en la poética, Goya haría lo suyo en la plástica. Ya en 1927, Ramón Gómez de la Serna se había empeñado en la rehabilitación de Goya, cuya «lección de contraste», es decir, de montaje heteróclito de tiempos y espacios constituye la base del humorismo español, que extrae su chispa «de un modo catastrófico, desesperado, barroco y con escasas palabras de agonía», en que el objetivo del artista "es volver de la nada y volverse a ir a la nada» (Gómez de la Serna, 1927:1). Poco después, ya publicado su libro sobre Goya (Gómez de la Serna, 1928), Ramón se dedicaría incluso a rescatar a otro olvidado, Sócrates, a 
partir de un libro de Arturo Cancela (Gómez de la Serna, 1929b). Es en esa lógica de las recuperaciones y restauraciones del pasado que podemos leer el siguiente texto de Gómez de la Serna:

Sobre la actual Pompeya hay una luz cenital que no hubo sobre la otra y que nos hace ver mejor la evocación del otro tiempo.

Lo que ha pasado en todos los edificios y en todos los templos es que la luz les ha penetrado por completo y ha iluminado sus memorias.

Bajo tanta luz caída desde lo alto y penetrando por donde antes hubo techos, se trasparece lo que cada cosa fue en el pasado y se encuentra el recuerdo formado y formalizado de cada edificio.

Lo que radica a Pompeya en su recinto actual como en el del pasado, es una luminosidad particular, como al trasluz de otro cerebro y otra idealidad.

Próximos a parajes de igual luz, o mejor dicho que debieran tener la misma luz, la de Pompeya tenía personalidad propia y era filtrada como por otros velos.

El sentido de la atmósfera pompeyana es el de un cerebro superpuesto a nuestro cerebro, un cerebro sombrilla que nos cubriese como medusa viva y transparente.

Bajo esa especie de pantalla vital de sustancia gris de otro tiempo que se superpone a nuestra cabeza vamos entreviendo todo reconstruido y como en día de mercado, hace siglos.

Algún candidato con la toga cándida pasa acompañado de los lictores que parecían defender su sombra inocente.

En las tapias aún se leen las invocaciones electorales:

«Los que deis el voto a Barca, seréis protegidos por la Diosa Venus».

Y como encumbramiento de los candidatos se leen adjetivaciones que llenan de rubor las paredes: «Verecundum adulescentum» (Joven lleno de modestia).

La parte de piel blanca y satinada, el estuque de la coquetería, más las diademas de la arquitectura, es lo que falta a esta especie de pueblo a medio desmoronar y atacado por la viruela del tiempo que es la Pompeya actual.

Ese segundo cerebro que envuelve nuestro cerebro de este tiempo va haciéndonos ver el revestimiento plástico que falta a las cosas, la parte de senos blandos que raspó la áspera caricia de los años. Lo que está intacto, las aras, las columnas que aún se están desperezando de lo mucho que han dormido enterradas en cenizas, los bustos envueltos por el traje ceñido del pedestal con silueta humana y alta base, todo eso que está intacto suelta humillo de evocación que acaba de plasmar todas las figuras y recubrir las aristas y suponer las guirnaldas de flores en que era rica Pompeya, pues en vez de velas se ofrendaba a los dioses y a las diosas flores entretejidas, trenzas de rosas, largos rosarios de claveles.

Las escaleras también se ofrecen a la planta ascendiente de la imaginación, remontándonos hasta los templos desaparecidos.

Yo he subido esas escaleras que ya parecen no ir a ningún sitio sino a la vana plataforma de las ruinas y al subir a su meta he sentido el palio de otro tiempo y el hermético sigilo de los templos, sobre todo el de Isis en el que aún hay como la sombra de una sacerdotisa que nos contiene con un gesto de su mano, como con un tope insobrepasable para toda alma galante, gesto que fue el que me detuvo siempre y no me dejó husmear en los rincones del sagrado templo, en esos ángulos de alcobas virginales que se atisban desde los atrios.

Lo que una ciudad tiene de invento engañoso encubrimiento de unas enhiestas pilastras, está desengańado y manifiesto en la Pompeya descaperuzada. Se ve la merienda de ideas, emociones, oraciones y consternaciones que es una ciudad, merienda de ideas sobre el inmenso estadium del campo, magismo e iluminismo de cámaras obscuras, de trincheras cerradas, de garitas lóbregas, somero artificio de biombos. ¡Tienen tantos miedos las multitudes! 
Lo que de afeite y retoque compone el asombro bello de una ciudad de templos e instituciones, ha sido descubierto como por un vitriolo eficaz, en esta ciudad cuya gracia se despertó repulida y readobada en mañanas espléndidas. Es interesante meditar en cómo vivió lo que ya no vive, para darnos cuenta de cómo dejará de vivir lo que actualmente vive. No se trata de adolorer el corazón, sino de confortarlo con la suave sonrisa de comprender las trasmutaciones y que no sobregrabe nuestra alma la superposición de lo edificado, la fantasmona realidad de lo encumbrado con paciente mezquindad. (Gómez de la Serna, 1929a)

El simple hecho de Ramón abordar, en 1929, en plena crisis del capital, la cuestión del eterno retorno en una crónica, objeto no solo desechable, sino de hecho desechado por la historiografía posterior, nos plantea de lleno aquello que Benjamin observa en un fragmento del Libro de los Pasajes:

La idea del eterno retorno hace del mismo acontecer histórico un artículo producido en masa. Pero esta concepción, bien que desde otro punto de vista podría decirse - desde su reversomuestra la huella de las circunstancias económicas a las que debe su repentina actualidad. Surgió en el momento en que, a consecuencia de una serie acelerada de crisis, disminuyó mucho la seguridad de las condiciones de vida. La idea del eterno retorno resultaba brillante debido a que ya no se podía contar incondicionalmente con un retomo de las condiciones a corto plazo, tal como hacía posible la eternidad. Las constelaciones cotidianas empezaron, muy lentamente, a serlo menos. Su retorno fue algo cada vez más raro y con ello pudo surgir la vaga sensación de que habría que contentarse con constelaciones cósmicas. En suma, la costumbre se las arregló para renunciar a algunos de sus derechos. Nietzsche dice «amo las costumbres efímeras", y ya Baudelaire había sido capaz durante toda su vida de adquirir costumbres fijas. Las costumbres son el armazón de la experiencia, las vivencias la destruyen. [J 62 a, 2]. (Benjamin, 2005:348)

Más aún, la cuestión del tiempo recurrente puede ser interpretada, pasiva, adaptativamente, como un perpetuum mobile, o al contrario, de manera activa, como rebelión contra la costumbre. El recuerdo verdadero, decía Benjamin, es épico y rapsódico. Vladimir Jankélévitch añadía además que el principio rapsódico se opone al principio sinfónico de la música de conservatorio, que responde al absolutismo legislador de la forma-sonata, mientras que el principio rapsódico de composición muestra que el lugar de un acontecimiento, en el mapa y en la duración, nunca es una mera contingencia subalterna, sino un medio de proporcionar simultáneamente una imagen de quien recuerda y de las capas que tuvimos que remover para alcanzar aquella de la que provienen los hallazgos. La rapsodia además libera, según Jankélévitch, fuerzas dionisíacas e insurreccionales que él identifica con Eugenio D’Ors, con el eterno barroquismo de la conciencia, es decir, con el abandono del tema por la espontaneidad pura del canto, de la voz ${ }^{6}$. El tema es una forma mélica, una elipsis, mientras que la voz rapsódica popular es una iteración sonora que no esconde su insistencia sin descomposición y se realiza según un orden acumulativo y torrencial, el del brío. Espontaneidad y facundia feliz, no otras serían sus premisas (Jankélévitch, 1939, 1955, 1989).

Pero, justamente, en su locuacidad, la idea del eterno retorno acaba derribando al historicismo del siglo XIX, en la medida en que cualquier valor es indicativo de algo que ya ocurrió en la noche inmemorial, motivo por el cual la tradición se vuelve mera fantasmagoría. Podríamos entonces leer su crónica pompeyana 
como una "pantalla vital», una prótesis proyectiva, simultáneamente estética y anestética, por lo tanto, como una mortificación, un súbito relampagueo entre muerte e imagen, una suerte de posmuerte, es decir, de destello fulgurante de lo que caduca, como Barthes o Derrida analizarían mucho después.

El texto de Ramón diseña así una escena heliotrópica, con «una luz cenital que no hubo sobre la otra y que nos hace ver mejor la evocación del otro tiempo». Esa luz penetra los edificios y hasta "ha iluminado sus memorias». Ante tamaña fulguración, «se trasparece lo que cada cosa fue en el pasado y se encuentra el recuerdo formado y formalizado de cada edificio», atravesado por "una luminosidad particular, como al trasluz de otro cerebro y otra idealidad $»^{7}$. Tal luz cenital exhibe entonces, descarnadamente, "un cerebro superpuesto a nuestro cerebro, un cerebro sombrilla que nos cubriese como medusa viva y transparente», expresión que súbitamente arma toda una constelación en que reconocemos objetos discursivos e icónicos tan dispares como «Aspecta Medusa» (1867) de Dante Gabriel Rossetti, "La cabeza de Medusa» (1922) de Sigmund Freud, y varios textos de Nietzsche, tales como El nacimiento de la tragedia (1870-71), donde Medusa señalaría el eterno conflicto entre lo apolíneo y lo dionisíaco, la alusión al eterno retorno en el final del cuarto libro de La gaya ciencia (1882) o la idea expuesta en los fragmentos póstumos (1822-1888) en el sentido de ver al propio pensamiento como cabeza de Medusa, una agonía congelada que todo petrifica. Pero hay más. El «cerebro sombrilla» nos remite directamente a la «bandeja de oro para las Salomé ultraístas» y a la "sombrilla de seda de equilibrista japonesa», esas que «bajo tu influencia concebimos/ y fornicamos los poetas salvajes", como declara Isaac del Vando-Villar (1924) en un poema dedicado precisamente a Ramón Gómez de la Serna. "La sombrilla blanca», por lo demás, es el título de uno de los sketches de Los muertos, las muertas, en que el solterón solo abdica de su ser celibato a causa de esa sombrilla etérea.

Llegamos así a la escena heliotrópica pompeyana por medio de una escalera, la del lenguaje equívoco, que no se decide entre con-temporizar y con-templar, «escaleras que ya parecen no ir a ningún sitio sino a la vana plataforma de las ruinas y al subir a su meta he sentido el palio de otro tiempo y el hermético sigilo de los templos», en una clara cita («Temple du Temps») de El cementerio marino de Valéry. Esas escaleras trazan un recorrido curvo y espiralado, como el emblema patafísico del Padre Ubu en el Ubu Roi (1896) de Jarry o el vorticismo de Ezra Pound, que lo llevan a concluir a Ramón que «es interesante meditar en cómo vivió lo que ya no vive, para darnos cuenta de cómo dejará de vivir lo que actualmente vive». En suma, en su crónica de 1929 Gómez de la Serna se detiene a las puertas de la posmuerte, como acatando la premisa benjaminiana formulada en Sobre el programa de la filosofía futura, "vivir quiere decir dejar trazos» (Benjamin, 1986:133).

\section{Cómo entendemos a la muerte en Buenos Aires}

Años más tarde, en plena segunda guerra, Macedonio Fernández le solicita a algunos escritores su visión acerca de la muerte, que por entonces todo lo tiñe, para publicar en su revista, Papeles de Buenos Aires. Un texto editorial, que no cabe duda de que sea del mismo Macedonio, aclara el contexto: 
De una humanidad todo lucha quisiéramos impulsar hacia una desvalorización de todos los motivos de lucha, gestionar un entusiasmo. Y para salir de luchas, nos parece que hay tres caminos: la metafísica inmortalista como religiosidad; el contacto y residencia preferente en medio de la naturaleza; o bien un gigantesco programa de Abundancia; excitar hacia una locura de producción, y locura de odio a todas las formas de la improducción y del engaño y destrucción. Hasta ahora solo hemos iniciado — en CóMO ENTENDEMOS A LA MUERTE EN BUENOS AIRES- la metafísica inmortalista, mediante el intento de que cada uno conjeture y cuente su día -o días- primero en el más allá, o sea en el no-aquí, no la agonía sino la posmuerte. Graziella Peyrou meditó ya «He aquí un primer día de muerto» y ahora Ramón Gómez de la Serna acude con su ardoroso socorro a nuestra invitación. (Anónimo, 1943:5)

Macedonio quería abandonar el agonismo dialéctico («una humanidad todo lucha») para, nietzscheanamente, buscar una transvaloración de los valores, un proyecto acefálico en que solo se pudiera considerar feliz, tal como proponía Bataille, aquel que experimentase el vértigo hasta el estremecimiento cabal, sin poder medir su caída, aunque recobrando, de pronto, su propia agonía como un goce capaz de transfigurar a todos los demás («una desvalorización de todos los motivos de lucha», dice Macedonio) y que generase entusiasmo, aquello que Bergamín, en Fronteras infernales de la poesía, describía como calle de dos manos, un ensimismamiento y un enfurecimiento paralelos, es decir, un entusiasmo, endiosamiento o deificación humana por lo absoluto, para lo cual es necesario, paralelamente, ensimismarse y enfurecerse: entrar y salir de uno mismo, que otra no es la característica del testimonio, dar cuenta de un proceso de desubjetivación. Macedonio ya no busca el ingenuo foquismo anarquista («el contacto y residencia preferente en medio de la naturaleza») y desdeña la salida capitalista («un gigantesco programa de Abundancia; excitar hacia una locura de producción, y locura de odio a todas las formas de la improducción y del engaño y destrucción»). No la agonía, que es trágica y dialéctica, sino la posmuerte, acefálica e iterativa.

La posmuerte se capta en imágenes porque la sobrevivencia anacroniza la historia: recordemos a Benjamin en su búsqueda de «las imágenes que, arrancadas de todos sus contextos anteriores, aparecen como objetos de valor en los aposentos sobrios de nuestra comprensión tardía». Como sabemos, en 1911, Julius von Schlosser propone el concepto de survival, en el campo de la antropología, como sobrevivencia de antiguas formas en prácticas asociadas a la cera, como la técnica escultórica egipcia de la cera perdida, concepto del que sacará provecho otro antropólogo británico, Edward B. Tylor. Pero si Tylor difícilmente excedía los marcos positivistas de la Primitive Culture, Aby Warburg, a partir de su estudio sobre el ritual de la serpiente, donde quería enlazar Atenas y Oraibi, encontraría un nuevo nexo entre tiempo y cultura, la vida póstuma o Nachleben, de tal modo que su Kulturwissenschaft es una suerte de traducción de la science of culture de Tylor, que acaba oponiendo la acronía etnológica a la simple y determinista evolución histórica. Progreso y decadencia, por el contrario, deberían ser puestos en tensión, de ahí en más, por un conjunto de teóricos tales como el propio Warburg, con su proyecto Mnemosyne (1924-9); Benjamin, con su idea de las imágenes dialécticas y del mismo Libro de los Pasajes (1927-1940), concebido como montaje literario, e incluso Ernst Bloch, quien ve al montaje, en Herencia de esta época (1935), como procedimiento de interrupción del flujo temporal.

Adoptando la posmuerte, Macedonio muestra no ser Juan B. Ambrosetti (1917), 
ni recluir la sobrevivencia en el estrecho margen de una superstición ${ }^{8}$. En efecto, la posmuerte, al oscilar entre fantasma y síntoma, nos propone un saber de la huella porque «la memoria es el medio de lo vivido». El vestigio exhibe, en primer lugar, una realidad negativa, un desecho, algo inactual o inusitado, pero también, y en consecuencia, un valor enmascarado, oculto, algo que pese a todo persiste y da testimonio. La posmuerte designa en pocas palabras una experiencia no solo de fractura, sino asimismo de espectralidad.

Al conocer la propuesta de Ramón Gómez de la Serna para la posmuerte, Macedonio inmediatamente la evaluó precisa, «sorprendente de hipótesis, conjeturas» (Fernández, 1976:63), por lo que no dudó en publicarla. La transcribo:

La primer [sic] sensación de muerto no se parecerá ni a los sueños, ni a las pesadillas, ni a los celos. Otra lámina sensible a otras sensibilizaciones. Nuestra percepción sin ni siquiera una memoria irónica y pequeñita de lo que sucedió.

Nada de aniquilamiento. Y si pudiéramos volver a sonreír dedicaríamos la última sonrisa a los que se quedaron y que aún temen la anonadación.

Tras esta introducción, Ramón aborda en lleno el problema de la aureola (sabemos que un poema como "Perte d'auréole», de Baudelaire, se lee con provecho a partir del concepto de aura que Leon Daudet propone y Benjamin rescata), concepto ese que cabría equiparar al de autenticidad, con que Luis Juan Guerrero traducía el aura benjaminiana, aunque no deje de tener vínculos también con otro concepto, el de redención (Erlösung) que, viniendo de Benjamin, ha encontrado nuevos desdoblamientos, más recientemente, en la obra de Giorgio Agamben. En una mezcla de voluntad de poder y eterno retorno, nos dice en efecto Ramón:

La aureola que todos tenemos y que es la que comunica su esencia espiritual a la corteza cerebral se desprenderá libre y buscará nuevos horizontes, otro espacio que el que vemos. No será primer día de muertos ese de la liberación, sino primer día de siempre.

Esa aureola o halo al que yo llamo en mi original concepción de la muerte: «disco acusativo», será lo que revele hasta el último de los secretos pensamientos y todo lo sucedido más todo lo subconsciente.

Un oprobio que se achacaba a Dios creyendo que Él llevaba nota de nuestras mezquindades, queda invalidado con esta idea del disco total de nuestra vida que se conocerá al tacto de la divinal inteligencia. (Tampoco vaya a creer nadie que se necesitará gramola y agujas nuevas). Revelada la grandeza o pequeñez de nuestra alma — nada de menudos pecados — caeremos, o ascenderemos y todo sucederá en menos del tiempo que lleva el salir por el balcón.

La muerte no es ya un doble antropomórfico, sino una dilución en lo absoluto en que nos salvamos del último engaño.

Es otra cosa, un espectáculo diferente, algo mucho mejor que el mejor amigo, olvido y libertad y el desprecio supremo de no saber lo que sucede. ¡Qué pequeños los objetos y los libros! Como prólogo de la variedad inacabable los libros estuvieron bien, fueron consuelo ciego y entretenimiento que nos entretuvo con fervor y que sirvió de merecimiento para que se nos concediese la amenidad ilimitada.

De esa afinidad con la gran inteligencia no gozarán los espíritus traidores o que se hayan degradado. Como habrán perdido su calidad caerán apagados en la nada.

Extrañeza y benevolencia serán las dos emociones del espíritu bueno al sentirse descerebrado, ya onda y no receptor. 
Nada de monigotadas porque el monigote se quedó yerto.

¿Y la Amada abandonada?

Si respeta el vacío de la ausencia —-molde perfecto de uno mismo— se unirá otra vez a uno

—ráfaga espiritual junto a ráfaga espiritual — y si no nos seremos incontrables —y como el vacío de mi ausencia habrá arruinado su vida— será de las aureolas caídas en la nada.

Tranquilos pues si habéis practicado con cierta persistencia el bien y no habéis rebajado vuestra aureola con ambiciones excesivas y tenaces.

$\mathrm{Ni}$ trajeados, ni parecidos, sino solo melenas de aureola, clima primaveral y cinematógrafo de toda la creación y con espacio inmenso y cuyas películas se verán superpatinando.

Lo importante es que no hayamos malogrado nuestra esencia, que hayamos sido inteligentes, perseverantes y buenos, pues automáticamente se verifica la absorción con la identidad celestial. «Amaste mi creación, la copiaste, buscaste en tu Subconsciente mis medusas misteriosas, las asterias inquietantes. Puedes pasar».

Esa será la supuesta absolución del más allá, la acogida sencilla de las aureolas o halos pervivientes y libertados. (Gómez de la Serna, 1943:5)

En la crónica de 1929, Ramón nos decía que el segundo cerebro que envuelve al cerebro de nuestro tiempo va haciéndonos ver el revestimiento plástico que falta a las cosas, es decir, las cosas no se captan por lo mimético o pictórico, sino por aquello que von Hildebrand o Carl Einstein llamarían das Plastische, lo escultórico. De allí provendría una carga emocional, un pathos, que le atribuye al arte de vanguardia otra síntesis de sentido y forma, es decir que, a través de la voluntad de absoluto, se capta una inconfundible angustia de lo moderno. Por ello ahora, en plena guerra, Ramón reitera que la aureola que todos tenemos es la que comunica su esencia espiritual a la corteza cerebral y es la que, al fin de los tiempos, se desprenderá libre y buscará otros horizontes, como pantalla proyectiva de otros trazos de luz, «cinematógrafo de toda la creación en sorprendente sección continua, en cines sin obscuridad y con espacio inmenso y cuyas películas se verán superpatinando».

La vida en ese círculo encantado de eterno retorno nos garantizará sin embargo una existencia que no abandona lo aurático. En El rastro (1914), Ramón le negaba a los objetos de feria el aura del anticuario porque tales objetos carecían del orgullo hipócrita de las cosas internadas de las tiendas de antigüedades; tampoco las consideraba cosas de museo, padeciendo largo infierno al tiempo que se vuelven socarronas, opresivas y autoritarias. Ni siquiera se las podía ver como ruinas históricas trascendentales, porque en las ruinas queda siempre algo que pervierte, un resto de supersticioso pasado. Eran tan solo cosas pegadas, decía, montajes de tiempos discontinuos, inculcados a sus añicos, pedazos de trascendencia incalculable ante los que se adquiere la seguridad de que, entre tantas piedritas minúsculas, está la gran piedra filosofal (Gómez de la Serna, 1931:23-26). En «La aureola libertada», en cambio, Ramón se decanta por las «medusas misteriosas» para alcanzar «las aureolas o halos pervivientes» (Fortleben), concepto que marca la traductibilidad entre textos y experiencias. Hay aquí una cierta superposición entre trazo y aureola. Benjamin, sin embargo, era muy preciso en la diferencia entre rastro y aura.

Huella y aura. La huella (Spur) es la aparición de una cercanía, por lejos que pueda estar lo que la dejó atrás. El aura es la aparición de una lejanía, por cerca que pueda estar lo que la provoca. En la huella nos hacemos con la cosa; en el aura es ella la que se apodera de nosotros [M 16 a, 4]. (Benjamin, 2005:450) ${ }^{9}$ 
En otras palabras, en la crónica de 1929 Pompeya aparece en close, por más distante que pueda estar lo que la sepultó. En la intervención de 1943, en cambio, emerge un distanciamiento, por más inminente que esté todo lo que lo provoca. En la crónica, Ramón se apodera de la cosa; en la reflexión sobre la aureola es ella la que lo toma y devora. Ejercicio de ateísmo radical, a la manera en que Martin Hüglund lee la desconstrucción y la espectrología, más que de mesianismo anateológico o ateológico, de estirpe bataillano-derrideana, como pensaba Werner Hamacher, Ramón nos propone en suma la «absolución del más allá», como rescate de la huella originaria que nos probaría que no hay vida sin posmuerte, o sea, de que solo disponemos de rastros eliminables y destruibles para un impredecible tiempo por venir, solo pensable a partir de una memoria colectiva, expropiada y desnacionalizada, que tratase de amenizar la dura constatación de que lo que sobrevive en un archivo lo hace solo por casualidad. Lo propio de la historia es la destrucción y el aniquilamiento indiferenciado de ciudades, bibliotecas o vidas.

«Libre de la memoria y de la esperanza,/ ilimitado, abstracto, casi futuro,/ el muerto no es un muerto: es la muerte» (Borges, 1974:33). Poco antes de la crónica heliotrópica de Pompeya, Borges lee a Eduardo Wilde, que es como leer al mismo Macedonio (el padre), un tabú:

Eduardo Wilde, tan abundoso de inteligencias, careció (o fingió carecer) de una inteligencia fundamental: la de barruntar que la posmuerte es vida y que ni está empedrada de calaveras ni se mide con féretros. Creyó ingenuamente que nosotros éramos capaces de inventar la Nada absoluta, de un momento a otro ¡nosotros tan incasables en vivir, que hasta nuestro sueño más descansado fabrica ensueños! Wilde prefirió negar la otra vida y experimentó sin duda tamaño chasco cuando lo trasmundearon de golpe. No le tengamos lástima: la lástima es siempre una descortesía y la negación o dubitación de la inmortalidad es siempre la mayor descortesía que podemos hacerle a los muertos. Más bien, envidiémosle las aventuras lindísimas que estará corriendo Wilde en el otro mundo. (Borges, 1928:161)

\footnotetext{
Notas

${ }^{1}$ Anticipada, incluso, en otra reseña, la de una obra del peruano Ventura García Calderon (1925), donde Benjamin enaltece las frases extremas, acompańadas del grito de los indios y narradas en la lengua extremadamente sobria del autor, él mismo indio.

${ }^{2}$ Medium es aquí traducido como medio pero quizás fuera más exacto verterlo como experiencia, como pura idea que suministra una imagen de memoria involuntaria, al modo proustiano, o como ambiente («la tierra es el medio en el que yacen enterradas las viejas ciudades») y así deslindar el término medio de un enfoque instrumental que no es el de Benjamin. ${ }^{3}$ En su ensayo de aprensión háptico-óptica, no menos que revolucionaria, del arte moderno, Carl Einstein juzgaba su Negerplastik (1915) una obra frustrante, un mero torso. Pero Luis Juan Guerrero, lector de Benjamin, expone en «Torso de la vida estética actual» (1949) una exaltación del fragmento argumentando que en una época de integridad no existe el torso o fragmento como fenómeno estético, porque cualquier aspecto
} 
aislado apunta simbólicamente hacia el complejo total. De esa manera «el arte hace visible el sentido último de las cosas, aún a través de sus pedazos rotos. En cambio, en una época de desintegración, esos trozos mutilados penetran en la experiencia estética por obra de la arbitrariedad del artista. Son "pre-textos" para exponer los méritos de un texto artístico. Pero también, en una dimensión oculta, son "símbolos" de un mundo de sentimientos privados, es decir, de fragmentos sueltos de una coexistencia en disolución». (Guerrero, 1950:1472)

${ }^{4}$ Kohan (2004); Simay (2005); Gagnebin (1993); Weigel (1999).

${ }^{5}$ La casa de los Vettii es un domus del cuarto estilo pompeyano que conserva inalterados sus frescos.

${ }^{6}$ La voz es el lugar de articulación entre el viviente y el lenguaje, es decir, donde se ejerce la Stimmung, el llamado que ejerce con pasión la invocación del lenguaje, como situación de este en una voz y del llamado inmemorial que la vocación histórica dirige al hombre. Solo el hombre posee y obedece a la Stimmung.

${ }^{7}$ Sobre el particular ver Cadava (2016).

${ }^{8}$ Con el concepto de superstición pretendía circunscribir Ambrosetti la psicología etnográfica o simplemente psicoetnografía, como la llama su autor, la historia de las religiones y la lógica social de los "pueblos primitivos» del Alto Paraná, una zona que mucho le interesó a Macedonio, porque allí quiso crear hacia 1897 una colonia anarquista con Arturo Muscari y Julio Molina y Vedia que, aunque fracasada, sobrevive en un proyecto de este último, «La Nueva Argentina» (1929-31).

${ }^{9}$ Para la conexión entre aura y arte, ver Hansen (2008:336-375); Krauss (1999:289-305); Costello (2005:164-184); Didi-Huberman (2009); Agamben (2009); Boucheron (2019).

\section{Referencias bibliográficas}

Agamben, G. (2009). Signatura rerum. Sobre el método. Adriana Hidalgo. Ambrosetti, J.B. (1917). Supersticiones y leyendas. La Cultura Argentina. Anónimo (1943). Papeles de Buenos Aires (2).

Benjamin, W. (1986). Sobre el programa de la filosofía futura [Traducción al español R. Vernango]. Planeta.

Benjamin, W. (1992a). Cuadros de un pensamiento. [Traducción al español S. Mayo y A. Mancini]. Imago Mundi.

Benjamin, W. (1992b). Desenterrar y recordar. En Cuadros de un pensamiento. [Traducción al español S. Mayo y A. Mancini] (pp. 118-119). Imago Mundi. [Hay otra traducción: (2010) «Excavar y recordar» en Imágenes que piensan. Obras, libro IV, vol. 1 (p. 350). Abada.] Benjamin, W. (2005). Libro de los Pasajes. Tiedemann, R. (Ed.) [Traducción al español Luis Fernández Castañeda, Isidro Herrera y Fernando Guerrero]. Akal.

Borges, J.L. (1928). Eduardo Wilde. En El idioma de los argentinos (p. 161). Gleizer.

Borges, J.L. (1974). Remordimiento por cualquier muerte. En Obra Completa (p. 33). Emecé. 
Boucheron, P. (2019). La Trace et l'aura. Vies posthumes d'Ambroise de Milan. Seuil.

Cadava, E. (2016). Trazos de luz. Tesis sobre la fotografia de la historia. [Traducción al español P. Cortés Rocca]. Palinodia.

Costello, D. (2005). Aura, face, photography. Re-reading Benjamin Today. En Benjamin, A. (Ed.) Walter Benjamin and Art (pp. 164-184). Continuum. DiAz, V. (2015). Barroco y modernidad en la teoría estética del siglo XX. (tesis inédita de doctorado). Universidad de Buenos Aires, Argentina.

DiAz, V. (2016). Walter Benjamin, la actualidad de la arqueología filosófica y el futuro de la filología. Filología (48), 113-126.

Didi-Huberman, G. (2009). La imagen superviviente. Historia del arte y tiempo de los fantasmas según Aby Warburg. Abada.

FernÁndez, M. (1976). Epistolario. Corregidor.

Gagnebin, J.M. (1993). Walter Benjamin. Os cacos da história. Brasiliense. Garcia Calderon, V. (1925). La vengeance du Condor. Sans-Pareil. Gómez de la Serna, R. (1927). El primer humorista español. La gaceta literaria, 1(13), 1.

Gómez de la Serna, R. (1928). Goya. La Nave.

Gómez de la Serna, R. (1929a). Luces de Pompeya. Plus Ultra, 14(157). Gómez de la Serna, R. (1929b). Reminiscencias de Sócrates (sobre Palabras socráticas a los estudiantes). Plus Ultra, 15(155).

Gómez de la Serna, R. (1931). El rastro. 2a ed. [s.n.].

Gómez de la Serna, R. (1943). La aureola libertada. Papeles de Buenos Aires (2), 5.

Gómez de la Serna, R. (1999). Obras completas, volumen 5. Galaxia Gutenberg.

Guerrero, L.J. (1950). Torso de la vida estética actual. En Actas del Primer Congreso Nacional de Filosofía (tomo III), 1472 organizado por Universidad Nacional de Cuyo.

Hansen, M.B. (2008). Benjamin's Aura. Critical Inquiry, 34(2), 336-375. JANKÉLÉVITCH, V. (1939). Maurice Ravel. Rieder.

JANKÉLÉVITCH, V. (1955). La Rhapsodie. Verve et improvisation musicale. Flammarion.

JANKÉLÉVITCH, V. (1989). Liszt et la rhapsodie. Essai sur la virtuosité. Plon. Конаn, M. (2004). Zona urbana. Ensayo de lectura sobre Walter Benjamin. Norma.

Krauss, R. (1999). «Reinventing the Medium». Critical Inquiry, (25), 289-305.

SimaY, P. (2005). Capitales de la modernité. Walter Benjamin et la ville. Ed. De l'Éclat.

VANDO-VILLAR, I. (1924). Luna llena. En La sombrilla japonesa. Tableros, s.p. Weigel, S. (1999). Cuerpo, Imagem y Espacio en Walter Benjamin. Una relectura. Paidós. 